\title{
Incidence of Chlamydia trachomatis infection in patients with reactive arthritis
}

\author{
Iwona Ostaszewska-Puchalska1,2, Bożena Zdrodowska-Stefanow ${ }^{3}$, Anna Kuryliszyn-Moskal ${ }^{4}$, \\ Violetta Bułhak-Kozioł ${ }^{1}$, Marianna Sokołowska ${ }^{1}$ \\ ${ }^{1}$ Diagnostic-Research Centre of Sexually Transmitted Diseases, Bialystok, Poland \\ ${ }^{2}$ The State Higher School of Computer Science and Business Administration, Institute of Medicine, Lomza, Poland \\ ${ }^{3}$ Department of Dermatology and Venerology, Medical University of Bialystok, Poland \\ ${ }^{4}$ Department of Rehabilitation, Medical University of Bialystok, Poland
}

\begin{abstract}
Objectives: The aim of the study was to evaluate the incidence of Chlamydia trachomatis in patients with reactive arthritis (ReA) within the area of the Podlaskie province (north eastern Poland). Material and methods: The study concerned 323 patients including 132 women and 191 men diagnosed with ReA. The material for $C$. trachomatis was collected from the urethra in men and the cervical canal in women. Also, every patient was tested for the presence of anti-C. trachomatis IgG class antibodies, while 121 individuals were additionally tested for IgA class antibodies. In the direct studies, the direct immunofluorescence (DIF) method or polymerase chain reaction (PCR) was used. The immunoenzymatic method was used to detect anti-C. trachomatis antibodies. The control group in the case of direct studies comprised 125 individuals, while in the case of serology research it included $127(\operatorname{lgG})$ and 109 (lgA) persons.

Results: Chlamydia trachomatis infection in the urethral and cervical smears was found in $42 \mathrm{pa}-$ tients (13.0\%) including 20 women (15.2\%) and 22 men (11.5\%). In the control group chlamydia was detected in 3 patients (2.4\%) including $4 \%$ of women and $2 \%$ of men. IgA class antibodies were present in 10/121 (8.3\%) patients, similarly in women and in men ( $8.2 \%$ and $8.3 \%$ respectively). In the control group the specific IgA class antibodies were found in 3/85 patients (3.5\%). Anti-C. trachomatis IgG antibodies were found in 70/323 patients (21.7\%), similarly in men and women.

Conclusions:

1. Chlamydia trachomatis is a common bacterial factor observed in the genitourinary system of patients with ReA. The outcomes of studies within the Podlaskie province indicate less frequent presence of chlamydial infection compared with Dolnośląskie province.

2. No correlations between detecting the presence of $C$. trachomatis in the urogenital tract and the presence of specific antibodies in the serum of ReA patients were observed.

3. Concurrent direct studies of the urogenital tract and a serological blood test increase the chance of detecting $C$. trachomatis infection.
\end{abstract}

Key words: reactive arthritis, Chlamydia trachomatis, polymerase chain reaction, direct immunofluorescence.

\section{Introduction}

Reactive arthritis (ReA) is caused by the infection of a distant location, mainly the digestive tract (ERA - enteric reactive arthritis) or genitourinary system [1]. It belongs to the group of spondyloarthropathy [2]. Sexually acquired reactive arthritis (SARA) is a subtype of

\footnotetext{
Address for correspondence:

Iwona Ostaszewska-Puchalska, Diagnostic-Research Centre of Sexually Transmitted Diseases, Św. Rocha 3, 15-879 Bialystok, Poland, e-mail: iwonapuch@poczta.fm

Submitted: 9.10.2014; Accepted: 16.02.2015
} 
ReA that typically affects lower limbs, mainly knees or ankles, and has a migrating and asymmetric nature [3].

One of the main causes of SARA is Chlamydia trachomatis infection, the most common bacterial factor transmitted sexually. Chlamydia trachomatis causes urethritis, epididymitis, prostatitis and conjunctivitis in men, while in women it causes cervicitis, inflammation of the organs of the small pelvis and pregnancy complications [4]. Also, it may lead to infertility both in men and women [4].

Patients with $C$. trachomatis infection of the genitourinary system with accompanying eye symptoms (mainly conjunctivitis, more rarely iritis) are also diagnosed with Reiter's syndrome [4, 5]. Moreover, changes in the skin and mucous membranes are commonly observed. Both Polish and world literature show great discrepancies in the obtained results of the studies on C. trachomatis infection in patients suffering from reactive arthritis $[6,7]$. No such studies have been carried out within the Podlaskie province so far.

\section{Aim of the study}

The aim of the study was to evaluate the incidence of $C$. trachomatis in patients with ReA within the area of the Podlaskie province (north eastern Poland).

\section{Material and methods}

The study concerned 323 patients aged 18-67 years including 132 (40.9\%) women and 191 (51.1\%) men. The patients diagnosed with ReA were referred to the Diagnostic-Research Centre of Sexually Transmitted Diseases in Bialystok mainly by rheumatologists and orthopaedists. Joint symptoms in the examined patients lasted from 3 months to 10 years. The studies were conducted in 2001-2012.

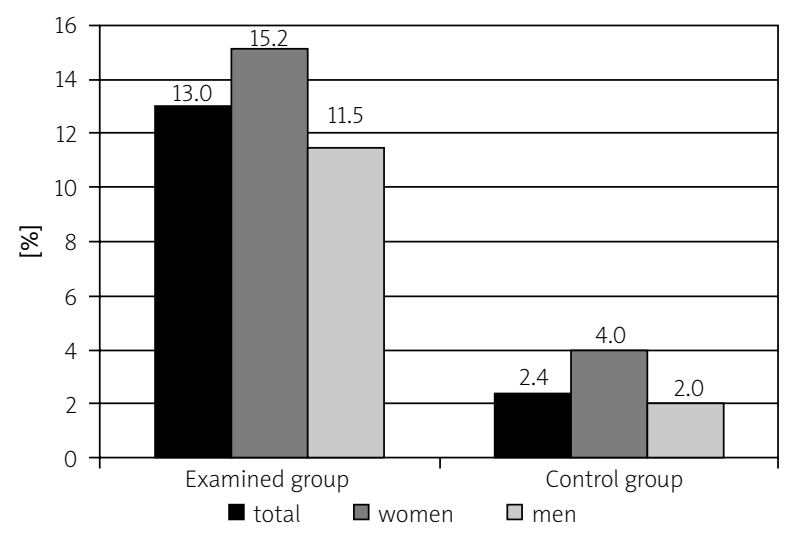

Fig. 1. Percentage incidence of $C$. trachomatis infection in the urethral or cervical smears in patients with reactive arthritis and in control group.
The study material comprised the urethra smear in men and cervical canal smear in women with the diagnosis of $C$. trachomatis. In all patients irrespective of gender blood was collected for the presence of antiC. trachomatis antibodies. Specific IgG antibodies were investigated in all 323 patients, and IgA antibodies in 121 (37.4\%) patients. Serological studies were conducted at the same time as direct tests of the urogenital tract.

The presence of $C$. trachomatis antigen was diagnosed using the direct immunofluorescence (DIF) method (DFA MicroTrak Direct) (132/323 patients $40.9 \%$ ), while bacterial genetic material was investigated using polymerase chain reaction (PCR) (Cobas Amplicor, Roche) (191/323 patients - 59.1\%). In the process of diagnosing the presence of anti-C. trachomatis antibodies of both IgA and IgG class the immunoenzymatic method (ELISA, Medac) was used. The control group for a direct immunofluorescence study comprised 125 patients aged 22-68 years including 100 men and 25 women, volunteers without urogenital or joint symptoms. In the case of labelling antiC. trachomatis antibodies in the serum the comparative groups comprised blood donors without urogenital or joint symptoms. In the case of IgG class antibodies they comprised 127 patients including 24 women and 103 men aged $17-56$ years, and for IgA class antibodies they comprised 109 patients aged 29-62 years including 85 men and 24 women.

In the statistical analysis the $\chi^{2}$ test was used. Results with $p<0.05$ were assumed significant.

The study was approved by the Bioethics Commission (approval no. R-I-003/9/2006).

\section{Results}

In the group of 323 patients 42 individuals (13.0\%) were diagnosed with $C$. trachomatis infection in the urethral or cervical smear. In 12/42 (28.6\%) patients the chlamydia infection was detected with DIF while in 30/42 (71.4\%) it was detected with PCR. Infection in the group of women was found in 20 individuals out of $132(15.2 \%)$ while in the group of men it was found in 22 patients out of 191 (11.5\%). In the control group chlamydia was observed in $3 / 125$ patients $(2.4 \%)$ including $1 / 25$ women (4.0\%) and $2 / 100$ men (2.0\%) (Fig. 1) $(p=0.0008)$.

Anti-C. trachomatis IgA class antibodies were detected in 10 out of 121 patients (8.3\%). Similar percentages were obtained both in female and male groups $(8.2 \%$ and $8.3 \%$ respectively). In the control group specific IgA class antibodies were found in 4/109 patients (3.7\%) including $1 / 24$ (4.2\%) women and $3 / 85$ men (3.5\%) (Fig. 2) $(p=0.1456)$. 


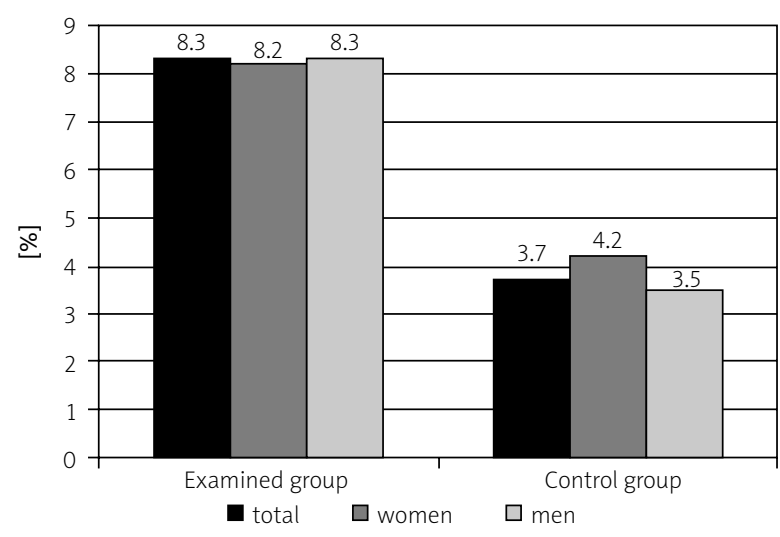

Fig. 2. Percentage incidence of anti-C. trachomatis IgA class antibodies in patients with reactive arthritis and control group.

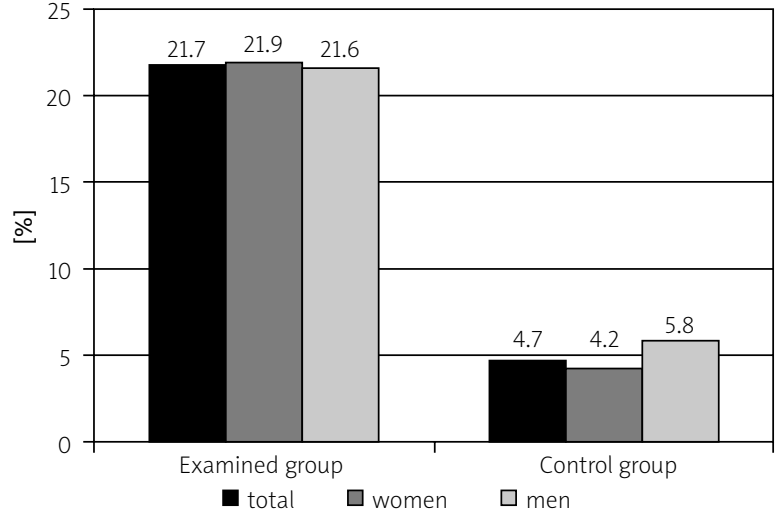

Fig. 3. Percentage incidence of anti-C. trachomatis IgG class antibodies in the blood of patients with reactive arthritis and in control group.

Table I. Presence of specific IgA and IgG antibodies in the serum of patients diagnosed with $C$. trachomatis infection in the urethra and/or cervix $(n=42)$

\begin{tabular}{|c|c|c|c|c|c|c|c|c|}
\hline \multirow[t]{3}{*}{ Chlamydia trachomatis } & \multicolumn{4}{|c|}{ IgA antibodies } & \multicolumn{4}{|c|}{ IgG antibodies } \\
\hline & \multicolumn{2}{|c|}{$(+)$} & \multicolumn{2}{|c|}{$(-)$} & \multicolumn{2}{|c|}{$(+)$} & \multicolumn{2}{|c|}{$(-)$} \\
\hline & $n$ & $\%$ & $n$ & $\%$ & $n$ & $\%$ & $n$ & $\%$ \\
\hline Urethra/cervix $(+)(n=42)$ & 0 & 0 & 42 & 100 & 14 & 33.3 & 28 & 66.7 \\
\hline
\end{tabular}

Anti-C. trachomatis IgG class antibodies were found in 70 out of 323 patients (21.7\%). The percentage of positive results was similar irrespective of gender (women $-21.9 \%$, men $-21.6 \%$ ). In the control group specific IgG class antibodies were detected in $7 / 127$ patients $(4.7 \%)$ including $1 / 24$ women (4.2\%) and 6/103 men (5.8\%) (Fig. 3) $(p=0.0000)$.

In the group of 42 patients with the diagnosis of C. trachomatis infection in the urethra or cervix, 14 patients $(33.3 \%)$ showed coexisting presence of specific IgG class antibodies in the serum, and no patient had IgA class antibodies (Table I).

Out of 121 patients, the presence of IgA class antibodies was observed in 10 (8.3\%) cases and IgG class antibodies in $16(13.2 \%)$ persons. The coexistence of both IgA and IgG class antibodies was observed only in 4 patients (3.3\%) (Table II).

\section{Discussion}

Chlamydia trachomatis is the most common bacterial factor transmitted sexually that causes SARA reactive arthritis. These bacteria are detected in both the genitourinary system and the synovial fluid, synovial membrane and synovial tissue [1, 8-10].

In the studied group, the presence of $C$. trachomatis in the genitourinary system was found in $13.0 \%$ of patients, more frequently in the female group (15.2\%) compared to
Table II. Coexistence of anti-C. trachomatis IgA and IgG antibodies in the serum of patients with reactive arthritis $(n=121)$

\begin{tabular}{|lccc|}
\hline \multicolumn{1}{|l|}{$\lg$} & $\mathrm{N}(+)$ & $\mathrm{N}(-)$ & Together \\
\hline $\mathrm{N} \mathrm{(+)}$ & 4 & 12 & 16 \\
\hline $\mathrm{N}(-)$ & 6 & 99 & 105 \\
\hline Together & 10 & 111 & 121 \\
\hline
\end{tabular}

the male group (11.5\%). Polish literature includes very few reports on the detection of $C$. trachomatis infection in patients with reactive arthritis or other inflammatory joint disorders [6, 11]. Choroszy-Król et al. [11] studied a group of 363 patients with arthritis and found C. trachomatis infection in the urethra and/or cervix in 47 (12.9\%) patients including $11.8 \%$ of patients with ReA.

In contrast to our studies, the authors detected the presence of chlamydia in urogenital tract more frequently in men (15.2\%) than in women (11.5\%) [11]. The studies were conducted using six different diagnostic techniques, most commonly DIF [11]. Świerkot et al. [6] used the amplification method and observed C. trachomatis infection in the urogenital tract in 42/87 (48.3\%) in patients with reactive arthritis. The observed discrepancies in the obtained outcomes may result from different methods used by the authors. 
Larsen et al. [12], using the immunoenzymatic method, observed C. trachomatis infection in 6/25 (24\%) patients with acute ReA. Kousa et al. [13], using cell culture, found chlamydia in 40/103 (38.8\%) men with the classic triad of conjunctivitis, urethritis and arthritis (formerly Reiter's syndrome). The infection was considerably more common in the group of patients with symptoms (39.2\%) compared to asymptomatic men (7.8\%). Keat et al. [8], using DIF and cell culture, observed C. trachomatis urogenital infection in $30 \%$ (3/10) of SARA patients and in no patient in the control group.

Many authors have detected chlamydia in the synovial fluid, synovial membrane or synovial tissue [5, 8, 10, 14-16]. Nikkari et al. [10] observed C. trachomatis DNA in synovial fluid in $33.3 \%$ of patients with ReA. Taylor-Robinson et al. [14] detected chlamydia in the synovial fluid and synovial membrane in ReA patients. Also, they diagnosed the presence of chlamydial elementary bodies with the DIF method in 4/8 (50\%) patients and chlamydial DNA in 5/8 (62.5\%) patients and in none of the patients from the control group. Similar studies were conducted by Kumar et al. [15, 16], whose analysis of synovial fluid in ReA patients revealed the presence of chlamydial elementary bodies with the DIF method in 4/12 patients (33.3\%) and chlamydial DNA (PCR method) in 5/16 (31.2\%) patients. Branigan et al. [9] used the PCR method and showed that chlamydial DNA is more commonly observed in synovial tissue (52.7\%) compared to synovial fluid (29.1\%).

In the whole group of studied patients with ReA specific anti-C. trachomatis IgA antibodies in the serum were observed in $8.3 \%$ of patients and IgG in $21.7 \%$ of the individuals in similar percentages in both men and women. Keat et al. [8] found specific IgA class antibodies in the serum in $9 / 10$ (90\%) patients with SARA, in 5/15 (33.3\%) patients with undifferentiated seronegative arthritis and in 1/15 (6.7\%) patients from the control group. Kumar et al. [16] observed the presence of specific antibodies in the serum of ReA patients in 2/16 (12.5\%) persons and in synovial fluid in $6 / 16$ (37.5\%). In the group of patients with undifferentiated spondyloarthropathy the authors detected IgA antibodies in the serum and synovial fluid in a similar percentage - in 3/22 (13.6\%) patients [16]. Larsen et al. [12] observed anti-C. trachomatis IgG antibodies in the serum in $28 \%$ of the patients with reactive arthritis and in $8 \%$ of patients from the control group. Nikkari et al. [17] investigated both IgA and IgG antibodies in the serum of patients suffering from arthritis. They observed the presence of the antibodies most commonly in patients with reactive arthritis (IgA - 78\%, IgG - 83\%) and least commonly in patients with rheumatoid arthritis (IgA - 20\%, IgG - 32\%). Pavlica et al. [5] observed specific IgG class antibodies in the se- rum of patients with the classic triad of conjunctivitis, urethritis and arthritis in $33.3 \%$ of the cases and in the synovial fluid in $11.1 \%$ of the individuals. No patient was diagnosed with IgA class antibodies in the serum or synovial fluid. Świerkot et al. [6] detected antichlamydial IgG antibodies in $64 \%$ of the patients and IgA in $18 \%$ of the serum of ReA patients. Some authors emphasise that IgA class antibodies are more commonly observed in patients with reactive arthritis and Reiter's syndrome and show higher values in the synovial fluid [14, 18, 19]. This indicates local production of specific antibodies of this class.

According to our own studies, concurrent co-existence of the antibodies of both classes was observed only in 4/121 (3.3\%) patients including 3 women and 1 man. In all those patients joint symptoms lasted from 3 to 6 months. In one of the female patients grade III smear was detected as well as uterine erosion, while the man showed the symptoms of chronic prostatitis. Interestingly, none of the patients was diagnosed with the presence of chlamydia in the urogenital tract. Further prospective monitoring of the clinical course of ReA in those patients could provide practical diagnostic clues.

The majority of patients with the presence of IgG antibodies and lack of IgA antibodies in the serum had a longer than a year history of joint symptoms. Therefore, no coexistence of the antibodies of both classes of immunoglobulins in those patients was observed. Lack of the presence of specific IgA antibodies in the serum of patients with $C$. trachomatis infection in the urogenital tract may be explained by the fact that joint symptoms in those individuals lasted more than 4-6 months, which may indicate a longer duration of an asymptomatic infection in the body. IgA class antibodies typically remain in the serum up to 6 months after the infection commencement, while IgG antibodies last for many years.

Based on many years of studies and our own observations as well as the observations of other authors, it seems that the best non-invasive method of diagnosing C. trachomatis infection in ReA patients is a concurrent chlamydial DNA test in the genitourinary system and labelling IgA and IgG antibodies in the serum. Due to the frequent asymptomatic nature of chlamydial infections, patients unaware of urogenital tract infection delay diagnosis and treatment and thus increase the risk of developing joint symptoms. In practice, patients report for a microbiological test at different points of the infection course. In the case of a C. trachomatis infection lasting for a few years, the chlamydial antigen or DNA in the urogenital tract as well as specific IgA antibodies in the serum are impossible to detect. 
The discrepancies in the results of both direct and serological studies of particular authors may result from the application of different methods and different groups of patients.

\section{Conclusions}

Chlamydia trachomatis is a common bacterial factor observed in the genitourinary system of patients with reactive arthritis. The outcomes of studies within the Podlaskie province indicate a less frequent presence of chlamydial infection compared with Dolnośląskie province. No similar studies have been conducted in other areas of the country.

No correlations between detecting the presence of C. trachomatis in urogenital tract and the presence of specific antibodies in the serum of ReA patients have been observed.

Concurrent direct studies of the urogenital tract and a serological blood test increase the chance of detecting C. trachomatis infection.

The authors declare no conflict of interest.

\section{References}

1. Kotake S, Nanke Y. Chlamydia-associated arthritis and enteropathic arthritis - two important spondyloarthritides. Nihon Rinsho Meneki Gakkai Kaishi 2011; 34: 121-130.

2. Quint KD, van der Helm-van Mil AH, Bergman W, Lavrijsen AP. Mucocutaneous abnormalities in Chlamydia trachomatis induced reactive arthritis. Ned Tijdschr Geneeskd 2010; 154: A1614.

3. Inman RD, Whittum-Hudson JA, Schumacher HR, Hudson AP. Chlamydia and associated arthritis. Curr Opin Rheumatol 2000; 12: 254-262.

4. Zdrodowska-Stefanow B, Ostaszewska I. Chlamydia trachomatis - infections in people. Volumed, Wrocław 2000.

5. Pavlica L, Drasković N, Kuljić-Kapulica N, Nikolić D. Isolation of Chlamydia trachomatis or Ureaplasma urealyticum from the synovial fluid of patients with Reiter's syndrome. Vojnosanit Pregl 2003; 60: 5-10.

6. Świerkot J, Choroszy-Król I, Marczyńska-Gruszecka K, et al. The role of diagnostic tests in the identification of Chlamydia trachomatis infection in reactive arthritis. Pol Arch Med Wewn 2003; 10: 711-718.

7. Savolainen E, Kettunen A, Närvänen A, et al. Prevalence of antibodies against Chlamydia trachomatis and incidence of C. trachomatis-induced reactive arthritis in an early arthritis series in Finland in 2000. Scand J Rheumatol 2009; 38: 353-356.

8. Keat A, Thomas B, Hughes R, Taylor-Robinson D. Chlamydia trachomatis in reactive arthritis. Rheumatol Int 1989; 9: 197-200.

9. Branigan PJ, Gérard HC, Hudson AP, et al. Comparison of synovial fluid as the source of nucleic for detection of Chlamydia trachomatis by polymerase chain reaction. Arthritis Rheum 1996; 39: 1740-1746.
10. Nikkari S, Puolakkainen $M$, Yli-Kerttula $U$, et al. Ligase chain reaction in detection of Chlamydia DNA in synovial fluid cells. Brit J Rheumatol 1997; 36: 763-765.

11. Choroszy-Król I, Ruczkowska J, Banasik B. Chlamydia trachomatis in urethral and cervical smears collected from patients with arthritis. Reumatologia 2001; 39: 133-139.

12. Larsen B, Birkelund S, Mordhorst CH, et al. The humor al immune response to Chlamydia trachomatis in patients with acute reactive arthritis. Br J Rheumatol 1994; 33: 534-540.

13. Kousa M, Saikku P, Richmond S, Lassus A. Frequent association of chlamydial infection with Reiter's syndrome. Sex Transm Dis 1978; 5: 57-61.

14. Taylor-Robinson D, Gilroy CB, Thomas BJ, Keat AC. Detection of Chlamydia trachomatis DNA in jones of reactive arthritis patients by polymerase chain reaction. Lancet 1992; 340: 81-82.

15. Kumar P, Khanna G, Batra S, et al. Chlamydia trachomatis elementary bodies in synovial fluid of patients with reactive arthritis and undifferentiated spondyloarthropathy in India. Int J Rheum Dis 2014 Apr 9. doi: 10.1111/1756-185X.12364.

16. Kumar P, Bhakuni DS, Rastogi S. Diagnosis of Chlamydia trachomatis in patients with reactive arthritis and undifferentiated spondyloarthropathy. J Infect Dev Ctries 2014; 8: 648-654.

17. Nikkari S, Puolakkainen $M$, Närvänen $A$, et al. Use of a peptide based enzyme immunoassay in diagnosis of Chlamydia trachomatis triggered reactive arthritis. J Rheumatol 2001; 28: 2487-2493.

18. Inman RD, Johnston ME, Klein MH. Analysis of serum and synovial fluid IgA in Reiter's syndrome and reactive arthritis. Clin Immunol Immunopathol 1987; 43: 195-203.

19. Bas S, Cunningham T, Kvien TK, et al. Synovial fluid and serum antibodies against Chlamydia trachomatis in different forms of arthritis: intra-articular IgA production in Chlamydia sexually acquired reactive arthritis. Br J Rheumatol 1996; 35 : 548-552. 